Artigo Original

Original Article

Luciene Stivanin $^{1}$ Maria Silvia Carnio ${ }^{1}$

Descritores

Fonoaudiologia Educação Docentes Crianças Habilidades Sociais

Keywords Speech Therapy Education Teachers Children Social Skills

Endereço para correspondência: Luciene Stivanin Centro de Docência e Pesquisa em Fisioterapia, Fonoaudiologia e Terapia Ocupacional, Universidade de São Paulo - USP

Rua Cipotânea, 51, Cidade

Universitária, São Paulo (SP), Brasil, CEP: 05360-160.

E-mail: lustivanin@gmail.com

Recebido em: Fevereiro 17, 2017

Aceito em: Maio 30, 2017

\section{Efeitos de um programa de linguagem no funcionamento social de crianças do Ensino Fundamental}

\author{
Effects of a language program in the social \\ functioning of children at elementary school
}

\begin{abstract}
RESUMO
Objetivo: o objetivo deste estudo foi descrever um programa de estimulação de linguagem, incluindo capacitação docente e atividades práticas em sala de aula, e investigar o efeito deste sobre o funcionamento social e problemas comportamentais de escolares do Ensino Fundamental. Método: participaram 136 crianças de seis salas de uma escola pública e seus professores. O grupo pesquisa recebeu o programa de estimulação de linguagem: 16 horas de capacitação docente e 9 encontros em sala de aula com atividades para os escolares. As atividades envolveram reflexão e prática com a estrutura narrativa. Os professores preencheram questionários sobre as habilidades sociais e problemas de comportamento de seus alunos, pré e pós-programa. Resultados: houve diferença estatisticamente significante entre pré e pós-programa dos grupos pesquisa em assertividade/desenvoltura social $\left(1^{\circ} \mathrm{e} 5^{\circ}\right.$ anos) e cooperação/afetividade ( $1^{\circ} \mathrm{e} 3^{\circ}$ anos). Nos grupos pesquisa, diferente dos escolares do $1^{\circ}$ e do $5^{\circ}$ anos, crianças do $3^{\circ}$ ano apresentaram maior evolução em suas habilidades de autocontrole, o que pode estar relacionado à menor frequência de problemas externalizantes neste grupo. Conclusão: o programa de linguagem proporcionou efeitos positivos nas habilidades de assertividade/desenvoltura social e cooperação/afetividade.
\end{abstract}

\begin{abstract}
Purpose: the purpose of this study was to describe a language stimulation program, including teacher training and practical activities in the classroom, and investigate the effectiveness of this action on the social functioning and behavioral problems of elementary school children. Methods: 136 children from six classrooms of a public school and their teachers participated in this research. Of these, half were given the language stimulation program: 16 hours of training for teachers and 9 meetings in the classroom with activities for students. The activities involved instruction for the use of language reflection and practice with the narrative structure. Teachers filled out questionnaires about the social skills and behavior problems of their students before and after the program. Results: there was no statistically significant difference between the research groups pre- and post- program in terms of assertiveness/ social resourcefulness (1st and 5 th grades) and cooperation/affection (1st and 3rd grades). In the research groups, children of the 3 rd grade, different from the 1 st and the 5 th grade, showed more evolution in their self-control abilities, which may be related to the lower frequency of externalizing problems in this group. Conclusion: the language program had positive effects on social assertiveness/resourcefulness skills and social cooperation/affection.
\end{abstract}

Trabalho realizado no Departamento de Fisioterapia, Fonoaudiologia e Terapia Ocupacional da Faculdade de Medicina da Universidade de São Paulo - USP - São Paulo (SP), Brasil.

${ }^{1}$ Centro de Docência e Pesquisa em Fisioterapia, Fonoaudiologia e Terapia Ocupacional, Universidade de São Paulo - USP - São Paulo (SP), Brasil.

Fonte de financiamento: nada a declarar.

Conflito de interesses: nada a declarar. 


\section{INTRODUÇÃO}

Sabe-se da importância da educação formal para o desenvolvimento econômico, social e político de um país. Porém, observa-se, no contexto brasileiro, o mau desempenho dos alunos em avaliações de disciplinas básicas como Português e Matemática.

Fatores biológicos, familiares e sociais interferem no desempenho escolar das crianças. Estruturas cerebrais responsáveis pelos processos críticos para a aprendizagem são vulneráveis à estimulação, ao estresse e à nutrição ${ }^{(1)}$. Resultante desta interação, as habilidades linguísticas e comportamentais têm sido alvo de estudo devido à sua importância para a aprendizagem no período escolar ${ }^{(2,3)}$.

O papel da linguagem oral na aprendizagem da leitura e escrita está bem descrito na literatura: habilidades fonológicas ${ }^{(4,5)}$, de vocabulário $^{(6,7)}$ e competência narrativa ${ }^{(8)}$. Enquanto o vocabulário receptivo e as habilidades sintáticas influenciam a aprendizagem, o vocabulário expressivo e a sintaxe são significativos também para o aprimoramento da comunicação interpessoal ${ }^{(9)}$.

Além da linguagem, outras habilidades permitem que as crianças se adaptem ao meio escolar e possam aprender. Classes específicas de comportamentos que permitem aos escolares lidarem de forma competente com as demandas de situações interpessoais são denominadas habilidades sociais. Na infância, são relevantes comportamentos como autocontrole e expressividade emocional (tolerar frustrações, expressar as emoções positivas e negativas); civilidade (cumprimentar pessoas, agradecer); empatia (ouvir e demonstrar interesse pelo outro, expressar compreensão pelo sentimento ou experiência do outro); assertividade (defender os próprios direitos, resistir à pressão de colegas); fazer amizades (fazer e responder perguntas, iniciar e manter conversação); solução de problemas interpessoais (identificar e avaliar possíveis alternativas de solução); e habilidades sociais acadêmicas (seguir regras ou instruções orais, participar de discussões) ${ }^{(10)}$.

Programas envolvendo práticas de linguagem oral mostraram resultados relevantes na aprendizagem de escolares, ao potencializar o desenvolvimento da leitura e/ou escrita ${ }^{(11-17)}$. Contudo, não foram localizados estudos sobre a influência destes programas no funcionamento social de escolares do Ensino Fundamental. Especificamente, escolares com melhores habilidades de linguagem têm mais condições para desenvolver relações interpessoais socialmente aceitáveis? Os programas de estimulação de linguagem em ambiente escolar proporcionam benefícios em outras habilidades além da aprendizagem?

Esta pesquisa teve por objetivo descrever a elaboração de um programa de estimulação de linguagem, para crianças do Ensino Fundamental I, bem como investigar seus efeitos sobre o funcionamento social e os problemas comportamentais destes escolares.

\section{MÉTODO}

Esta pesquisa foi realizada após aprovação do Comitê de Ética da Instituição, sob o n ${ }^{\circ} 183 / 13$ e assinatura dos Termos de Consentimento Livre e Esclarecido pelos pais e/ou responsáveis pelas crianças. Foi realizada em duas etapas: 1) elaboração de um programa de estimulação de linguagem; e 2) aplicação do programa em escolares do Ensino Fundamental I.

\section{1) Elaboração do Programa}

O Programa foi elaborado para ser aplicado em duas fases: capacitação dos professores e realização de atividades com os alunos.

A capacitação dos professores teve a finalidade de aprimorar o conhecimento sobre comunicação e linguagem, por meio de aulas expositivas com conteúdo teórico, vídeos e atividades de reflexão. Os temas explanados basearam-se na literatura sobre a integração entre vários fatores (biológicos e sociais) durante o desenvolvimento; a importância da linguagem oral para aprendizagem e relacionamento interpessoal; a importância de uma comunicação eficaz e interação saudável entre os professores e os alunos ${ }^{(2-9,18)}$. Os temas abordados nesta parte do programa estão dispostos no Quadro 1. O conteúdo foi redigido em forma de apostilas e gravado em CDs.

Quadro 1. Temas abordados na parte teórica do programa

Parte I. Desenvolvimento da linguagem oral e da comunicação: O que é comunicação e as habilidades necessárias para comunicação eficiente; O que é linguagem oral: como a criança produz os sons, dá nome às coisas, forma as frases e discursos complexos; Sobre o que as crianças falam e como desenvolvem as narrativas; Recepção das informações e processamento auditivo; Fatores relacionados ao desenvolvimento da linguagem e sinais de alerta.

Parte II. O papel da linguagem oral na aprendizagem da linguagem escrita: O que é leitura e escrita; O que é necessário para desenvolver a linguagem escrita; Processamento auditivo e processamento visual; Memória, atenção, funções executivas; Capacidades metalinguísticas: consciência fonológica, morfológica e metatextual, Sinais de problemas.

Parte III. O papel da linguagem nas relações interpessoais: Processamento de emoções; Linguagem como ferramenta de pensamento, controle das emoções e do comportamento; Ações e linguagem; Desenvolvimento de linguagem x comportamento.

Parte IV. A criança está na escola - o que ela faz: Integração entre habilidades auditivas, linguísticas, sociais, emocionais; Quando há problemas: exemplos.

Parte V. As crianças chegaram à escola - por que algumas não aprendem?: Transtornos específicos de aprendizagem; Dificuldades secundárias a transtornos neuropsiquiátricos; Dificuldades secundárias a alterações de linguagem oral; Comorbidades. O que as crianças trazem de seus ambientes?: Condições socioeconômicas, Vulnerabilidade social, Maus tratos e suas consequências no desenvolvimento e aprendizagem.

Parte VI. Como posso ajudar?: Este é meu aluno: o que ele faz, facilidades e dificuldades, de onde veio e o que trouxe; O que posso mudar em mim: como é minha comunicação, o que ela causa nos alunos e como utilizá-la de forma positiva; Complementando minhas aulas: mudanças de postura e no ambiente; Parceria Fonoaudiologia e Professores: atividades de consciência fonológica, fonêmica, domínio ortográfico, elaboração narrativa. 
Para as atividades elaboradas para a sala de aula, conforme descritas no Quadro 2, foi priorizada a estimulação da linguagem envolvendo narrativas orais, que envolvem diversos processos complexos: para estabelecer esta relação entre os eventos e produzir oralmente o discurso narrativo, a criança deve coordenar várias habilidades linguísticas incluindo o processamento fonológico, semântico e sintático ${ }^{(19)}$, além de funções executivas, atencionais e afetivas ${ }^{(20)}$. Neste sentido, a narrativa é um aspecto importante da linguagem com relevância direta no desenvolvimento social e acadêmico de crianças $^{(21)}$. A programação envolveu identificação, exploração e produção dos elementos da narrativa, com utilização de apoio oral, imagens e escrita $^{(14,22)}$. Foram planejados nove encontros semanais, com os materiais condizentes ao nível de escolaridade da amostra, selecionados em parceria com os professores.

\section{2) Aplicação do Programa}

\section{Local e características socioeconômicas}

A pesquisa foi realizada com escolares do Ensino Fundamental I de uma escola pública estadual, cujo Índice de Desenvolvimento da Educação Básica é 5,3 (meta: 4,4) ${ }^{(23)}$.

O Indicador de Nível Socioeconômico (INSE) dos alunos da escola está classificado no grupo IV (grupo de I a VII), no qual as famílias indicaram que há em casa bens elementares (rádio, uma geladeira, um ou dois telefones celulares, um banheiro e dois ou mais televisores em cores); bens complementares (videocassete ou DVD, máquina de lavar roupas e computador, com ou sem internet) e bens suplementares, (freezer, um telefone fixo e um carro). Além disso, não contratam empregada mensalista; a renda familiar mensal está entre um e dois salários mínimos; e seus pais e/ou responsáveis completaram o ensino fundamental, podendo ter concluído ou não o ensino médio, mas não completaram o ensino superior.

\section{Participantes}

Os cinco anos escolares foram convidados a participar da pesquisa $\left(1^{\circ}\right.$ ao $5^{\circ}$ ano). O critério de inclusão foi o ano escolar e o consentimento dos responsáveis. Os critérios de exclusão foram a presença de acuidade visual, auditiva e desempenho cognitivo abaixo dos padrões de normalidade, crianças com outras patologias associadas como síndromes genéticas, neurológicas, neuropsiquiátricas ou deficiência intelectual, constantes no prontuário escolar ou indicados pelos professores no decorrer do programa. Além disso, os alunos que não estiveram presentes em $75 \%$ dos encontros e/ou não completaram avaliação e reavaliação também foram exclusos da pesquisa.

Não houve número suficiente de professores do $2^{\circ}$ e do $4^{\circ}$ anos que tenham aceitado participar da pesquisa. Com os professores do $1^{\circ}, 3^{\circ}$ e $5^{\circ}$ anos, que mostraram interesse para participar do programa, foi realizado sorteio para definir os grupos pesquisa e controle.

A amostra foi constituída por 136 escolares do $1^{\circ}, 3^{\circ}$ e $5^{\circ}$ anos, sendo duas classes por ano, ou seja, uma foi o grupo pesquisa (GP) e a outra, o grupo controle (GC). Os escolares dos GPs

Quadro 2. Objetivos e estratégias das atividades

Encontros: $1^{\circ}$ ao $3^{\circ}$ : Conscientização, compreensão e uso da comunicação de forma eficiente.

Material: Apostila elaborada pela pesquisadora com narrativa sobre amigos que vão descobrir a importância da leitura e da comunicação. Estratégias: 1. Elaboração de listas: benefícios de leitura, importância de ouvir e de falar bem; situações em que podemos falar livremente e quando não podemos chegar falando; 2. Identificação de imagens contendo atos prejudiciais à audição, ao uso abusivo da voz e ofensas ao ouvinte; 3. Dinâmicas para ressaltar a dificuldade em transmitir informações na fala, com gritos ou quando não se ouve o falante; 4 . Jogo de mímica: cada aluno do grupo pega uma carta com uma sentença e deve comunicá-la ao grupo por meio de mímica. Se o grupo acertar, ganha ponto; 5. Jogo do grito: cada aluno do grupo pega uma carta contendo uma função (protesto, pedido, etc.) e deve comunicá-la ao grupo com um grito. Se o grupo acertar, ganha ponto; 6 . Jogo de falar baixo: cada aluno do grupo pega uma carta contendo uma função (protesto, pedido, etc.) e deve comunicá-la falando muito baixo; 7. Identificação de sentimentos em diversas situações do cotidiano: Quando ouvimos coisas boas e ruins, quando ficamos felizes ou tristes; 8 . Jogo da reversão: Cada aluno de um grupo pega uma sentença (elogio ou ofensa). Se tirar elogio ganha ponto e, se tirar ofensa, só ganha ponto se conseguir reverter o conteúdo; 9 . Jogo do elogio: cada aluno fala uma característica positiva do colega. Escrever lista na lousa.

Encontros $4^{\circ}$ ao $7^{\circ}$ : Identificação e exploração dos elementos da narrativa: cenário/setting, complicação/problema, resposta interna, plano/tentativa, consequência/resolução, reação(22), por meio de histórias de livros infantis.

Estratégias: Marcação de cada elemento narrativo com uma cor; explicação de cada elemento e associação a símbolos; uso de perguntas norteadoras: Quem participa da história? Onde acontece a história? Quando acontece a história? Qual problema ocorreu nesta história? O que aconteceu? Como os participantes se sentiram? Como pensaram em resolver e o que tentaram? Qual foi o resultado? Como reagiram após o resultado?

Discussão sobre a mudança dos personagens da história durante os fatos, de acordo com os problemas e resultados, sobre as várias tentativas para resolver um único problema.

Encontros $8^{\circ}$ e $9^{\circ}$ : Adição de elementos e geração de narrativas a partir de problemas.

Material: Folha com os símbolos e frases norteadoras de uma narrativa e os lembretes sobre parágrafos, pontuação, título, diálogos e revisão. Estratégias: Criação de duas histórias: uma com o problema: Um menino (ou menina) que perdeu alguma coisa muito importante; outra com os personagens: João, um menino triste, que não tem sonhos e não acredita em nada; Uma mulher inteligente, muito simpática e solidária.

Atividades complementares realizadas em outro momento pelo professor: Identificação dos elementos da história escrita; completar os parágrafos com passagens da narrativa; técnica de cloze - escolher as palavras adequadas (adjetivos, verbos, substantivos), produção escrita a partir de sequências. 
participaram do programa e seus professores da capacitação. Os escolares dos GCs participaram apenas das avaliações pré e pós-programa e seus professores não receberam nenhum tipo de instrução. Os dados descritivos encontram-se na Tabela 1. O GP foi composto por maior quantidade de meninas no $3^{\circ}$ e $5^{\circ}$ anos, mas não houve diferença estatística quanto ao gênero e idade entre os GP e GC em cada ano.

\section{Realização das ações programadas}

A capacitação dos professores dos GPs ocorreu em quatro encontros quinzenais, com duração de quatro horas cada. Nestas ocasiões, os professores receberam uma apostila com os conteúdos planejados e materiais de apoio teórico-prático gravados em CDs, para consulta durante os procedimentos práticos. No último encontro, foi apresentada a estrutura da parte prática para aplicação aos alunos em sala de aula. Os professores auxiliaram no ajuste quanto ao horário, tempo de duração e seleção das histórias trabalhadas nas práticas de narrativas.

Depois da capacitação, deu-se início ao trabalho em sala de aula, uma vez por semana, durante 50 minutos, no período escolar.

Foram realizados nove encontros, com as atividades aplicadas em conjunto entre a pesquisadora e os professores do GP. Os alunos ouviram e/ou leram as narrativas e as atividades envolviam identificação, exploração dos elementos narrativos e produção, por meio oral e/ou escrito. Não foram feitas intervenções específicas na produção escrita, relacionadas às convenções textuais ou erros de ortografia.

Em outro dia da semana, o professor, sozinho, administrava outra atividade complementar, pré-elaborada em conjunto.

\section{Instrumentos de avaliação e reavaliação}

Inventário de Habilidades Sociais, Problemas de Comportamento e Competência Acadêmica para crianças $^{(24)}$; os professores dos grupos GP e GC responderam a um questionário específico. A Escala de habilidades sociais contém 22 itens e avalia o conjunto de comportamentos sociais do repertório de um indivíduo, agrupados em quatro fatores que são: Responsabilidade, Autocontrole, Assertividade/Desenvoltura Social, Cooperação/Afetividade. As questões possuem três alternativas de respostas em relação à frequência de ocorrência (Nunca $=0$, Algumas Vezes $=1$ e Muito Frequente $=2$ ). A escala de indicadores de comportamentos problemáticos contém 14 itens, nos quais são avaliados os comportamentos que competem ou

Tabela 1. Caracterização dos indivíduos quanto ao nível de escolaridade, idade e gênero

\begin{tabular}{ccccc}
\hline $\begin{array}{c}\text { Ano } \\
\text { escolar }\end{array}$ & Grupo & $\begin{array}{c}\text { Média de idade } \\
\text { e dp }\end{array}$ & $\begin{array}{c}\text { Gênero } \\
\text { feminino }\end{array}$ & $\begin{array}{c}\text { Gênero } \\
\text { masculino }\end{array}$ \\
\hline \multirow{2}{*}{$1^{\circ}$ ano } & GP & $6,5 a(d p=0,5)$ & $15(50 \%)$ & $15(50 \%)$ \\
& GC & $6,6 a(d p=0,7)$ & $15(48,3 \%)$ & $16(51,7 \%)$ \\
$3^{\circ}$ ano & GP & $8,5 a(d p=0,5)$ & $13(65 \%)$ & $7(35 \%)$ \\
& GC & $8,5 a(d p=0,5)$ & $7(43,8 \%)$ & $9(56,2 \%)$ \\
$5^{\circ}$ ano & GP & $10,3 a(d p=0,5)$ & $14(73,6 \%)$ & $5(26,4 \%)$ \\
& GC & $10 a(d p=0,9)$ & $10(50 \%)$ & $10(50 \%)$ \\
\hline
\end{tabular}

GP: grupo pesquisa; GC: grupo controle; dp: desvio padrão; a=ano interferem na aprendizagem e no desempenho das habilidades (externalizantes, internalizantes e hiperatividade). Os itens são respondidos em relação à frequência de ocorrência, com três alternativas de resposta (Nunca $=0$, Algumas Vezes $=1$ e Muito Frequente=2).

Os questionários foram preenchidos pelos professores pré e pós a aplicação do Programa. Os resultados foram analisados por uma psicóloga colaboradora da equipe. Foram computados os escores gerais e fatoriais para cada escala. Quanto maiores os escores de habilidades, mais elaborado é o repertório social e quanto mais elevado o escore de indicadores de comportamento problemático, maior a necessidade de suporte para a criança.

\section{Análises estatísticas}

Foram utilizadas técnicas básicas de análise exploratória como média, mediana, desvio padrão e análises de frequência. Utilizou-se a análise estatística não paramétrica Wilcoxon Signed Rank para a comparação de médias dentro de cada item de avaliação nos grupos pesquisa e controle, pré e pós-aplicação do programa. Todos os testes de hipóteses desenvolvidos neste trabalho consideraram uma significância de 5\%, isto é, a hipótese nula foi rejeitada quando $\mathrm{p}$-valor foi menor que 0,05 .

\section{RESULTADOS}

\section{Comparação intragrupos e intergrupos pré-programa}

Conforme observado na Tabela 2, no momento pré-programa, não houve diferença significativa entre o $\mathrm{GP} \mathrm{e} \mathrm{o} \mathrm{GC}$ do $1^{\circ}$ ano, em habilidades sociais e problemas de comportamento. No $3^{\circ}$ ano, houve diferença significativa entre o GP e o GC nos fatores autocontrole, assertividade/desenvoltura social e comportamentos externalizantes. No $5^{\circ}$ ano, houve diferenças significativas entre o GP e o GC nos fatores responsabilidade, cooperação/afetividade e comportamentos externalizantes. Tanto no $3^{\circ}$ como no $5^{\circ}$ ano, o GP apresentou melhor desempenho nos fatores descritos.

$\mathrm{Na}$ comparação das pontuações entre os anos escolares, tanto no GP quanto no GC, alunos do $5^{\circ}$ ano tiveram pontuação menor do que alunos do $1^{\circ}$ e do $3^{\circ}$ ano em habilidades sociais e maior em problemas de comportamento, o que indica maior frequência de problemas neste ano.

\section{Comparação intragrupos e intergrupos pós-programa}

Foi possível observar melhores pontuações em determinadas habilidades em todos os anos no momento pós-programa. No $1^{\circ}$ ano, as pontuações do GP foram maiores pós-programa nos fatores assertividade/desenvoltura social, cooperação/afetividade (Tabela 3), o que indica o desenvolvimento destas habilidades sociais, não observado no GC. Os alunos do $3^{\circ}$ ano do GP mostraram aumento da pontuação nos fatores autocontrole, assertividade/desenvoltura social, cooperação/afetividade e menores no total de problemas de comportamento (Tabela 4). Alunos do $5^{\circ}$ ano do GP tiveram maiores pontuações do que o GC nos fatores assertividade/desenvoltura social, cooperação/afetividade (Tabela 5). 
Tabela 2. Comparação entre grupo pesquisa e grupo controle no pré-programa

\begin{tabular}{|c|c|c|c|c|c|c|c|c|}
\hline \multirow{2}{*}{ Variáveis } & \multirow[b]{2}{*}{ Ano } & \multicolumn{3}{|c|}{ Grupo Pesquisa } & \multicolumn{3}{|c|}{ Grupo Controle } & \multirow{2}{*}{$\mathrm{p}$-valor } \\
\hline & & Média & Mediana & Desvio Padrão & Média & Mediana & Desvio Padrão & \\
\hline \multirow{3}{*}{$\begin{array}{l}\text { Habilidades sociais - total } \\
\text { (pontuação 0-44) }\end{array}$} & $1^{\circ}$ ano & 37,83 & 42,00 & 9,33 & 39,23 & 42,00 & 4,81 & 0,3682 \\
\hline & $3^{\circ}$ ano & 37,90 & 38,00 & 4,29 & 31,81 & 32,00 & 4,45 & $0,0004^{*}$ \\
\hline & $5^{\circ}$ ano & 31,84 & 32,00 & 4,23 & 28,15 & 28,50 & 5,38 & $0,0333^{\star}$ \\
\hline \multirow{3}{*}{$\begin{array}{l}\text { Responsabilidade } \\
\text { (pontuação 0-12) }\end{array}$} & $1^{\circ}$ ano & 10,20 & 12,00 & 3,24 & 10,77 & 11,00 & 1,31 & 0,4554 \\
\hline & $3^{\circ}$ ano & 11,90 & 12,00 & 0,31 & 11,75 & 12,00 & 0,58 & 0,4419 \\
\hline & $5^{\circ}$ ano & 10,89 & 12,00 & 1,63 & 8,90 & 9,00 & 2,67 & $0,0078^{\star}$ \\
\hline \multirow{3}{*}{$\begin{array}{c}\text { Autocontrole } \\
\text { (pontuação 0-16) }\end{array}$} & $1^{\circ}$ ano & 13,23 & 15,50 & 4,45 & 14,16 & 15,00 & 2,05 & 0,7402 \\
\hline & $3^{\circ}$ ano & 13,20 & 14,00 & 1,91 & 10,31 & 10,00 & 2,30 & $0,0003^{\star}$ \\
\hline & $5^{\circ}$ ano & 10,42 & 10,00 & 1,89 & 9,75 & 9,00 & 2,02 & 0,0952 \\
\hline \multirow{3}{*}{$\begin{array}{l}\text { Assertividade/desenvoltura } \\
\text { social (pontuação 0-10) }\end{array}$} & $1^{\circ}$ ano & 8,90 & 10,00 & 2,02 & 8,65 & 10,00 & 1,72 & 0,3518 \\
\hline & $3^{\circ}$ ano & 8,00 & 8,00 & 1,69 & 5,56 & 6,00 & 1,63 & $0,0004^{*}$ \\
\hline & $5^{\circ}$ ano & 5,74 & 6,00 & 1,88 & 5,75 & 6,00 & 1,12 & 0,4092 \\
\hline \multirow{3}{*}{$\begin{array}{c}\text { Cooperação/afetividade } \\
\text { Pontuação (0-6) }\end{array}$} & $1^{\circ}$ ano & 5,50 & 6,00 & 1,11 & 5,65 & 6,00 & 1,05 & 0,4878 \\
\hline & $3^{\circ}$ ano & 4,75 & 5,00 & 1,21 & 4,19 & 4,50 & 1,68 & 0,3501 \\
\hline & $5^{\circ}$ ano & 4,79 & 5,00 & 1,18 & 3,75 & 4,00 & 0,85 & $0,0067^{\star}$ \\
\hline \multirow{3}{*}{$\begin{array}{c}\text { Problemas de } \\
\text { comportamento - total } \\
\text { (pontuação 0-28) }\end{array}$} & $1^{\circ}$ ano & 3,27 & 0,00 & 6,75 & 2,23 & 0,00 & 5,36 & 0,7652 \\
\hline & $3^{\circ}$ ano & 0,75 & 0,00 & 2,02 & 3,25 & 2,00 & 4,52 & $0,0029^{\star}$ \\
\hline & $5^{\circ}$ ano & 5,26 & 2,00 & 6,76 & 8,25 & 8,00 & 3,37 & $0,0045^{\star}$ \\
\hline \multirow{3}{*}{$\begin{array}{l}\text { Problemas externalizantes } \\
\quad \text { (pontuação 0-10) }\end{array}$} & $1^{\circ}$ ano & 1,40 & 0,00 & 3,38 & 0,81 & 0,00 & 2,43 & 0,8353 \\
\hline & $3^{\circ}$ ano & 0,25 & 0,00 & 0,79 & 1,56 & 0,00 & 2,71 & $0,0264^{\star}$ \\
\hline & $5^{\circ}$ ano & 2,11 & 0,00 & 3,57 & 3,70 & 4,00 & 2,23 & $0,0141^{*}$ \\
\hline \multirow{3}{*}{$\begin{array}{l}\text { Hiperatividade } \\
\text { (pontuação 0-8) }\end{array}$} & $1^{\circ}$ ano & 1,20 & 0,00 & 2,31 & 0,90 & 0,00 & 1,76 & 0,7587 \\
\hline & $3^{\circ}$ ano & 0,25 & 0,00 & 0,79 & 0,88 & 0,00 & 1,78 & 0,2201 \\
\hline & $5^{\circ}$ ano & 1,58 & 0,00 & 2,14 & 3,10 & 3,00 & 1,25 & $0,0025^{\star}$ \\
\hline \multirow{3}{*}{$\begin{array}{l}\text { Problemas internalizantes } \\
\text { Pontuação (0-8) }\end{array}$} & $1^{\circ}$ ano & 0,67 & 0,00 & 1,30 & 0,52 & 0,00 & 1,36 & 0,5073 \\
\hline & $3^{\circ}$ ano & 0,25 & 0,00 & 0,64 & 0,81 & 0,00 & 1,17 & 0,0658 \\
\hline & $5^{\circ}$ ano & 1,58 & 1,00 & 1,57 & 1,45 & 1,00 & 1,05 & 1,0000 \\
\hline
\end{tabular}

Tabela 3. Comparação da evolução nas habilidades sociais e problemas de comportamento entre grupo pesquisa e grupo controle do $1^{\circ}$ ano

\begin{tabular}{|c|c|c|c|c|c|c|c|c|}
\hline \multirow{2}{*}{ Variáveis } & & \multicolumn{3}{|c|}{ Grupo Pesquisa } & \multicolumn{3}{|c|}{ Grupo Controle } & \multirow{2}{*}{$\mathrm{p}$-valor } \\
\hline & & Média & Mediana & Desvio Padrão & Média & Mediana & Desvio Padrão & \\
\hline $\begin{array}{l}\text { Habilidades sociais - total } \\
\text { (pontuação } 0-44 \text { ) }\end{array}$ & Pós & 40,13 & 42,50 & 6,38 & 39,81 & 42,00 & 4,78 & 0,2290 \\
\hline \multirow{3}{*}{$\begin{array}{l}\text { Responsabilidade } \\
\text { (pontuação } 0 \text {-12) }\end{array}$} & Pré & 10,20 & 12,00 & 3,24 & 10,77 & 11,00 & 1,31 & \\
\hline & Pós & 10,40 & 12,00 & 2,94 & 10,84 & 11,00 & 1,27 & 0,6671 \\
\hline & Diferença & 0,20 & 0,00 & 0,66 & 0,06 & 0,00 & 0,57 & \\
\hline $\begin{array}{c}\text { Autocontrole } \\
\text { (pontuaçãa } 0 \text {-16) }\end{array}$ & Diferença & 0,50 & 0,00 & 1,61 & 0,48 & 0,00 & 1,06 & \\
\hline \multirow{3}{*}{$\begin{array}{l}\text { Assertividade/desenvoltura } \\
\text { social (pontuação 0-10) }\end{array}$} & Pré & 8,90 & 10,00 & 2,02 & 8,65 & 10,00 & 1,72 & \\
\hline & Pós & 9,53 & 10,00 & 0,97 & 8,71 & 10,00 & 1,74 & $0,0118^{*}$ \\
\hline & Diferença & 0,63 & 0,00 & 1,22 & 0,06 & 0,00 & 0,44 & \\
\hline $\begin{array}{l}\text { Cooperação/afetividade } \\
\text { Pontuação (0-6) }\end{array}$ & Pré & 5,50 & 6,00 & 1,11 & 5,65 & 6,00 & 1,05 & \\
\hline $\begin{array}{c}\text { Problemas de } \\
\text { comportamento - total } \\
\text { (pontuação 0-28) }\end{array}$ & Diferença & $-0,20$ & 0,00 & 1,95 & $-0,48$ & 0,00 & 1,18 & \\
\hline \multirow{3}{*}{$\begin{array}{l}\text { Problemas externalizantes } \\
\text { (pontuação 0-10) }\end{array}$} & Pré & 1,40 & 0,00 & 3,38 & 0,81 & 0,00 & 2,43 & \\
\hline & Pós & 1,47 & 0,00 & 3,28 & 0,71 & 0,00 & 2,25 & 0,4182 \\
\hline & Diferença & 0,07 & 0,00 & 0,69 & $-0,10$ & 0,00 & 0,60 & \\
\hline \multirow{3}{*}{$\begin{array}{l}\text { Hiperatividade } \\
\text { (pontuação 0-8) }\end{array}$} & Pré & 1,20 & 0,00 & 2,31 & 0,90 & 0,00 & 1,76 & \\
\hline & Pós & 1,07 & 0,00 & 1,93 & 0,61 & 0,00 & 1,58 & 0,0513 \\
\hline & Diferença & $-0,13$ & 0,00 & 1,01 & $-0,29$ & 0,00 & 0,59 & \\
\hline \multirow{3}{*}{$\begin{array}{l}\text { Problemas internalizantes } \\
\text { Pontuação }(0-8)\end{array}$} & Pré & 0,67 & 0,00 & 1,30 & 0,52 & 0,00 & 1,36 & \\
\hline & Pós & 0,53 & 0,00 & 1,11 & 0,42 & 0,00 & 1,31 & 0,7158 \\
\hline & Diferença & $-0,13$ & 0,00 & 0,57 & $-0,10$ & 0,00 & 0,30 & \\
\hline
\end{tabular}

*= significante; Teste de Wilcoxon; $\mathrm{p}<0,05$ 
Tabela 4. Comparação da evolução nas habilidades sociais e problemas de comportamento entre grupo pesquisa e grupo controle do $3^{\circ}$ ano

\begin{tabular}{|c|c|c|c|c|c|c|c|c|}
\hline \multirow{2}{*}{ Variáveis } & & \multicolumn{3}{|c|}{ Grupo Pesquisa } & \multicolumn{3}{|c|}{ Grupo Controle } & \multirow{2}{*}{ p-valor } \\
\hline & & Média & Mediana & Desvio Padrão & Média & Mediana & Desvio Padrão & \\
\hline \multirow{3}{*}{$\begin{array}{c}\text { Habilidades sociais - } \\
\text { total } \\
\text { (pontuação 0-44) }\end{array}$} & Pré & 37,90 & 38,00 & 4,29 & 31,81 & 32,00 & 4,45 & \\
\hline & Pós & 43,70 & 44,00 & 0,66 & 32,06 & 32,00 & 4,78 & $<0,0001^{*}$ \\
\hline & Diferença & 5,80 & 5,50 & 4,25 & 0,25 & 0,00 & 0,68 & \\
\hline \multirow{3}{*}{$\begin{array}{l}\text { Responsabilidade } \\
\text { (pontuação 0-12) }\end{array}$} & Pré & 11,90 & 12,00 & 0,31 & 11,75 & 12,00 & 0,58 & \\
\hline & Pós & 12,00 & 12,00 & 0,00 & 11,69 & 12,00 & 0,70 & 0,1037 \\
\hline & Diferença & 0,10 & 0,00 & 0,31 & $-0,06$ & 0,00 & 0,25 & \\
\hline \multirow{3}{*}{$\begin{array}{c}\text { Autocontrole } \\
\text { (pontuação 0-16) }\end{array}$} & Pré & 13,20 & 14,00 & 1,91 & 10,31 & 10,00 & 2,30 & \\
\hline & Pós & 15,70 & 16,00 & 0,66 & 10,38 & 10,00 & 2,28 & $<0,0001^{*}$ \\
\hline & Diferença & 2,50 & 2,00 & 2,14 & 0,06 & 0,00 & 0,25 & \\
\hline \multirow{3}{*}{$\begin{array}{l}\text { Assertividade/ } \\
\text { desenvoltura social } \\
\text { (pontuação 0-10) }\end{array}$} & Pré & 8,00 & 8,00 & 1,69 & 5,56 & 6,00 & 1,63 & \\
\hline & Pós & 10,00 & 10,00 & 0,00 & 5,81 & 6,00 & 1,91 & $0,0008^{*}$ \\
\hline & Diferença & 2,00 & 2,00 & 1,69 & 0,25 & 0,00 & 0,58 & \\
\hline \multirow{3}{*}{$\begin{array}{c}\text { Cooperação/afetividade } \\
\text { Pontuação (0-6) }\end{array}$} & Pré & 4,75 & 5,00 & 1,21 & 4,19 & 4,50 & 1,68 & \\
\hline & Pós & 6,00 & 6,00 & 0,00 & 4,19 & 4,50 & 1,68 & $0,0001^{*}$ \\
\hline & Diferença & 1,25 & 1,00 & 1,21 & 0,00 & 0,00 & 0,00 & \\
\hline Problemas de & Pré & 0,75 & 0,00 & 2,02 & 3,25 & 2,00 & 4,52 & \\
\hline \multirow{2}{*}{$\begin{array}{l}\text { comportamento -total } \\
\text { (pontuação 0-28) }\end{array}$} & Pós & 0,10 & 0,00 & 0,45 & 3,69 & 2,00 & 5,02 & $0,0179^{*}$ \\
\hline & Diferença & $-0,65$ & 0,00 & 2,11 & 0,44 & 0,00 & 0,81 & \\
\hline \multirow{3}{*}{$\begin{array}{c}\text { Problemas } \\
\text { externalizantes } \\
\text { (pontuação 0-10) }\end{array}$} & Pré & 0,25 & 0,00 & 0,79 & 1,56 & 0,00 & 2,71 & \\
\hline & Pós & 0,00 & 0,00 & 0,00 & 1,94 & 1,00 & 3,21 & 0,0115 \\
\hline & Diferença & $-0,25$ & 0,00 & 0,79 & 0,38 & 0,00 & 0,81 & \\
\hline \multirow{3}{*}{$\begin{array}{l}\text { Hiperatividade } \\
\text { (pontuação 0-8) }\end{array}$} & Pré & 0,25 & 0,00 & 0,79 & 0,88 & 0,00 & 1,78 & \\
\hline & Pós & 0,10 & 0,00 & 0,45 & 0,94 & 0,00 & 1,77 & 0,3506 \\
\hline & Diferença & $-0,15$ & 0,00 & 0,93 & 0,06 & 0,00 & 0,25 & \\
\hline \multirow{3}{*}{$\begin{array}{l}\text { Problemas internalizantes } \\
\text { Pontuação (0-8) }\end{array}$} & Pré & 0,25 & 0,00 & 0,64 & 0,81 & 0,00 & 1,17 & \\
\hline & Pós & 0,00 & 0,00 & 0,00 & 0,81 & 0,00 & 1,17 & 0,1185 \\
\hline & Diferença & $-0,25$ & 0,00 & 0,64 & 0,00 & 0,00 & 0,00 & \\
\hline
\end{tabular}

Tabela 5. Comparação da evolução nas habilidades sociais e problemas de comportamento entre grupo pesquisa e grupo controle do $5^{\circ}$ ano

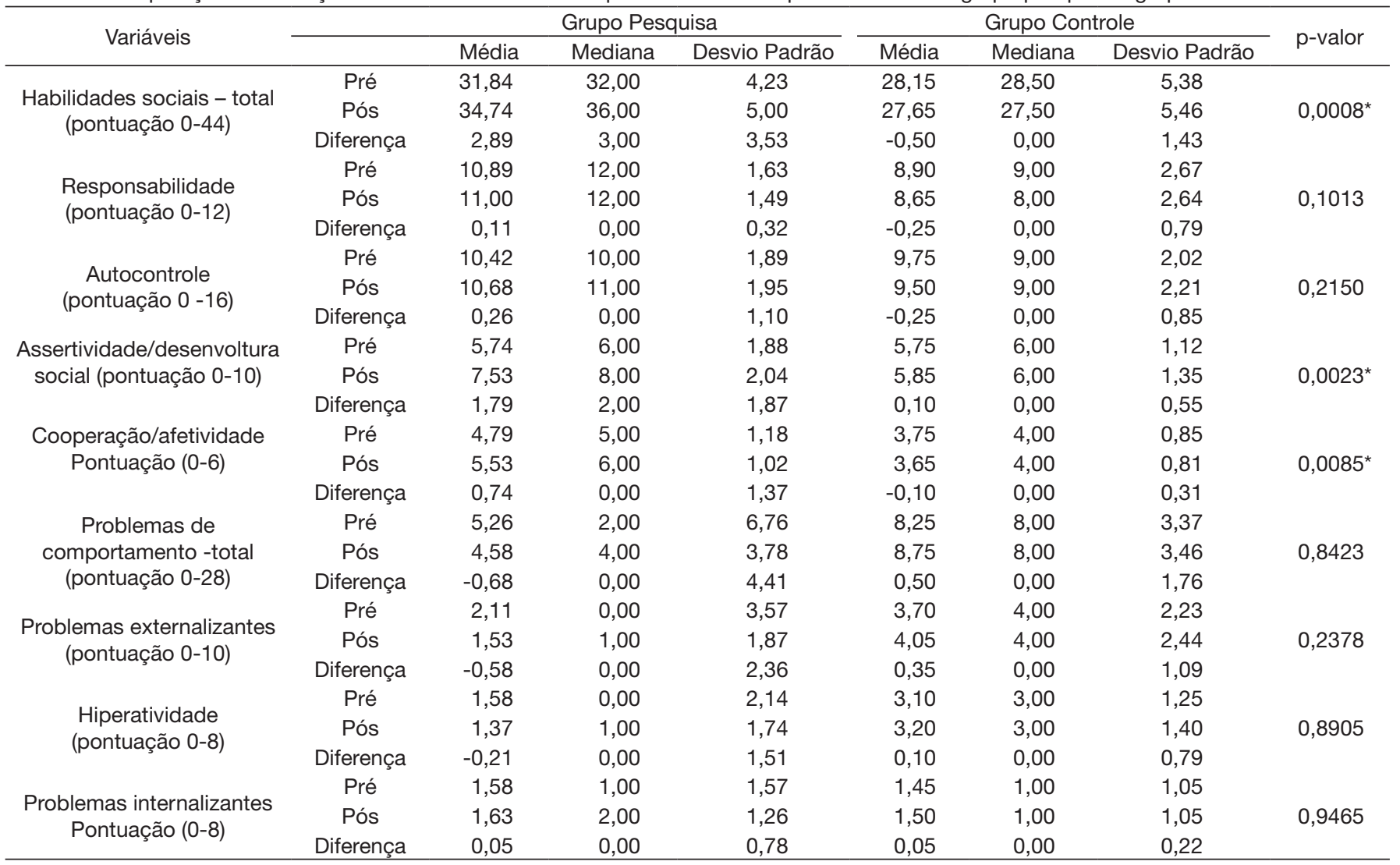

*= significante; Teste de Wilcoxon; $\mathrm{p}<0,05$ 


\section{DISCUSSÃO}

O objetivo desta pesquisa foi descrever a elaboração de um programa de estimulação de linguagem e verificar seus efeitos no funcionamento social de escolares do ensino fundamental. Os principais resultados apontam melhora em determinadas habilidades sociais e no comportamento dos escolares do GP, de forma diferente entre os anos escolares. O papel do programa de linguagem, entretanto, será discutido considerando fatores metodológicos que podem ter contribuído.

No $1^{\circ}$ ano, as médias das pontuações de habilidades sociais e problemas de comportamento foram semelhantes entre os alunos do GP e do GC. Na avaliação pós-programa, os alunos do GP apresentaram melhora em habilidades de assertividade/desenvoltura social e de cooperação/afetividade.

No $3^{\circ}$ ano, os alunos do GP apresentaram melhora em autocontrole, assertividade/desenvoltura social, cooperação/afetividade e comportamento, evolução não observada no GC. Porém, no momento pré-programa, como já apresentavam funcionamento melhor nestas habilidades, podem ter aproveitado mais facilmente $o$ programa, sugerindo um efeito que não foi exclusivo do programa e sim gerado também pelo amadurecimento e escolarização. Ressalta-se, entretanto, que, no fator cooperação/afetividade, alunos do GP e GC eram semelhantes no pré-programa e o grupo que recebeu o programa mostrou evolução significativa pós-programa.

No $5^{\circ}$ ano, os alunos do GP melhoraram suas pontuações em assertividade/desenvoltura social e em cooperação/afetividade, mais do que os alunos do GC. Porém, no pré-programa, os alunos do GP já se beneficiavam por serem mais responsáveis e cooperativos e terem menos problemas externalizantes do que o GC, o que pode ter auxiliado na melhora da assertividade durante a aplicação do programa, sugerindo o mesmo ocorrido com alunos do $3^{\circ}$ ano, ou seja, efeitos do programa associados ao amadurecimento e escolarização.

Embora no $1^{\circ}$ ano os efeitos do programa sejam evidentemente associados ao programa, no $3^{\circ}$ e no $5^{\circ}$ ano as diferenças entre GP e GC, observadas no pré-programa, devem ser levadas em conta. O critério adotado para a designação das classes em GP e GC foi o sorteio, para evitar que a equipe escolar destinasse a classe com maior problemática para o programa. Outra cautela foi trabalhar apenas com professores que manifestaram interesse na participação do programa. Por isto, o $2^{\circ}$ e o $4^{\circ}$ anos foram excluídos, pois somente um professor de cada teve interesse; haveria o risco de o GC, nestes casos, pertencerem a professores que não tivessem, no momento, foco na melhora da classe quanto às habilidades do programa.

A pesquisa foi realizada em escola pública com foco na estimulação da linguagem e não intervenção junto a alunos com dificuldades e/ou problemas. O programa foi elaborado para atender à classe com todos os alunos ao mesmo tempo, no horário regular das aulas, não havendo formação de diferentes grupos ou saída da classe para atividades específicas. Por isto, não foi possível controlar as características do funcionamento social e do comportamento dos escolares, nos GPs e no GC, tampouco propor ações específicas para diferentes grupos.
Considerando apenas os fatores cujas pontuações foram semelhantes entre GP e GC no pré-programa, os efeitos foram observados em assertividade/desenvoltura social e cooperação/afetividade no $1^{\circ}$ ano, cooperação/afetividade no $3^{\circ}$ ano e assertividade/desenvoltura social no $5^{\circ}$ ano. Embora tratados com cautela, tendo em vista o melhor funcionamento já no pré-programa do GP dos anos mais escolarizados, estas são as habilidades mais atingidas pelo programa de linguagem.

Ser assertivo significa ser capaz de expressar-se de forma direta e clara, levando em consideração os direitos da outra pessoa envolvida na situação ${ }^{(25)}$. Ou seja, envolve comportamentos que expressam traquejo nas relações como apresentar-se a novas pessoas sem precisar mandar, questionar de forma educada quando não concorda, dizer coisas sobre si em situações apropriadas e fazer amigos facilmente. Já cooperação/afetividade dizem respeito a comportamentos que contribuem para o andamento de uma atividade e o atendimento de necessidades dos outros, como oferecer ajuda espontaneamente e juntar-se a um grupo ${ }^{(24)}$.

Crianças com pouca iniciativa e desenvoltura social apresentam dificuldades para fazer amizades, pois apresentar-se a novas pessoas, juntar-se a grupos de atividade sem ser mandado, convidar outros para vir à sua casa e iniciar conversações são comportamentos desafiadores para elas ${ }^{(26)}$ e crianças que não cooperam podem ser rejeitadas ou não chamadas a participar do grupo. As habilidades de cooperação têm sido reconhecidas e empiricamente constatadas como importantes fatores de proteção para dificuldades de aprendizagem, no contexto de sala de aula $^{(27)}$.

Os alunos participaram das atividades e jogos de competição em pequenos grupos, o que propiciou momentos de atuação conjunta, estimulando a cooperação. As tarefas abordaram a importância de ouvir o outro, de falar sem gritar e de não ofender, durante as quais os alunos eram estimulados a identificar situações do dia a dia em que falhas na comunicação causaram problemas e a pensar sobre maneiras mais eficazes de interação verbal. Todos estes aspectos eram retomados pelos professores durante outros dias da semana, o que pode ter auxiliado a recordação e uso de ações assertivas.

Outras atividades propiciaram a exploração de elementos da narrativa como cenário/setting, complicação/problema, resposta interna, plano/tentativa, consequência/resolução, reação. Quanto maior o nível de conhecimento da criança sobre a estrutura narrativa, mais coerente e coeso pode ser o texto elaborado por ela ${ }^{(21)}$, mostrando que estas atividades auxiliam na organização da linguagem. Mas, além de refletir sobre a estrutura e a organização do texto (consciência metatextual), foram trabalhados também os conteúdos da história ao explorar as características dos personagens, seus sentimentos, intenções e motivações, as relações causais entre as ações, as alternativas e decisões para resolução dos problemas. Isto pode permitir à criança o entendimento sobre o outro, seus sentimentos e atitudes.

A reflexão sobre a estrutura das narrativas, os recontos e as elaborações exigiram dos escolares atenção ao tema, manutenção da informação durante o acesso a outras informações da memória de longo prazo, elaboração da estrutura linguística, planejamento motor e expressão verbal e, por envolver diversos 
domínios linguísticos, cognitivos e emocionais, contribuíram para o desenvolvimento das crianças.

Os professores receberam informações sobre a relação entre a aprendizagem, o domínio linguístico e as relações sociais. Foram abordados temas como o ambiente familiar em que as crianças se desenvolveram e os conceitos que formaram, bem como sentimentos e atitudes que podem ser disparados em reação às posturas do adulto. Entender e refletir sobre o papel do ambiente, a importância da função docente no desenvolvimento/acolhimento dos escolares e os resultados mais produtivos de uma relação interpessoal saudável pode ter levado os professores a aprimorarem suas posturas, atitudes e falas dirigidas aos alunos. Estudos apontam que o volume e qualidade das estratégias comunicativas utilizadas por professores em sala de aula propiciam ganhos no vocabulário e desenvolvimento da linguagem ${ }^{(18)}$. Quando as crianças podem se expressar, sentem-se seguras no contexto de interação e podem dispensar atos prejudiciais ao desenvolvimento e interação social, como gritos, xingamentos, agressões físicas e verbais ${ }^{(28)}$.

Apenas alunos do $3^{\circ}$ ano do GP tiveram pontuações significativamente maiores em habilidades de autocontrole. $\mathrm{O}$ autocontrole se refere a comportamentos emitidos em situação de conflito ou que requerem controlar os próprios comportamentos, como controlar irritação, reagir de forma apropriada à pressão dos colegas, responder apropriadamente a gozações, aceitar ideias dos colegas, ignorar distrações e se dar bem com pessoas diferentes ${ }^{(24)}$. Também e somente no $3^{\circ}$ ano, escolares do GP mostraram melhora na pontuação total de problemas de comportamento, que envolve a soma da pontuação dos fatores externalizantes (comportamentos que envolvem agressão física ou verbal com outros e baixo controle do humor), internalizantes (comportamentos indicativos de ansiedade, tristeza, solidão e baixa autoestima) e hiperatividade (comportamentos que envolvem movimentação excessiva, inquietação e reações suicidas). As habilidades de autocontrole predizem variações significativas nos escores globais de problemas de comportamento e especificamente nos escores de hiperatividade e problemas externalizantes, pois controlar a irritação e raiva, aceitar críticas e finalizar discordâncias calmamente poderiam reduzir, na criança, a probabilidade de apresentar problemas comportamentais ${ }^{(29)}$. Crianças com maiores capacidades de autorregulação apresentam melhor funcionamento social, o que influencia o desempenho acadêmico ${ }^{(18)}$. Já foi apontado anteriormente que estes resultados devem ser analisados levando em conta que o GP já era mais habilidoso do que o GC pré-programa. Entretanto, os alunos do $5^{\circ}$ ano do GP também apresentavam menos problemas de comportamento do que o GC e não tiveram melhora em seu autocontrole. Na comparação entre os anos escolares no préprograma, os alunos do $3^{\circ}$ ano são mais habilidosos socialmente e apresentam menos problemas de comportamento do que os do $5^{\circ}$ ano, sugerindo que a menor ocorrência de comportamentos externalizantes está associada ao autocontrole.

Quanto à responsabilidade, a diferença na pontuação entre os dois momentos de avaliação foi pequena e não significativa. Ou seja, mesmo após a aplicação do programa, não houve diferenças nas ações dos alunos voltadas ao cuidado com as tarefas, materiais e classe, assim como nas instruções. No $1^{\circ}$ ano, os alunos do GP e GC tiveram aumentos sutis na pontuação em habilidades de autocontrole, mas suas médias são superiores às do $5^{\circ}$ ano. $\mathrm{O}$ fato de a idade ser menor e de estarem no primeiro ano do ensino fundamental aponta que o contorno feito pelo professor é suficiente para que tenham controle de suas atitudes nas interações sociais, pelo menos na sala de aula. Já os alunos mais velhos e escolarizados, pela adaptação e desenvolvimento de hábitos sociais, podem ser menos vulneráveis ao controle do professor e a programas de estimulação.

Esta pesquisa apresenta limitações e direções para novas explorações. Uma das limitações foi discutida inicialmente, em virtude de sua importância na interpretação dos dados e se refere ao melhor funcionamento do GP do $3^{\circ}$ e $5^{\circ}$ anos, no momento pré-programa. Com o envolvimento de mais classes de cada ano escolar e aumento da amostra, seria possível controlar as características pré-programa, analisando as pontuações apenas daqueles que são semelhantes no início.

Como a utilização da narrativa, principal componente do programa, envolve vários domínios linguísticos, seria importante estudar quais permitem melhor desenvolvimento das habilidades sociais. Além disto, não foram avaliadas as funções executivas, que podem influenciar as habilidades dirigidas aos outros, a reflexão e cooperação como melhor alternativa em interações sociais. Futuras pesquisas podem avaliar a interação entre linguagem oral/escrita, as funções executivas, funcionamento acadêmico e social, em crianças participando de programas de estimulação, a fim de desenvolver programas de promoção da saúde mental em ambiente escolar, com custos viáveis e resultados efetivos.

Também não foi medida a satisfação dos alunos quanto ao programa, mas a participação voluntária e a assiduidade às atividades podem ser um indicador de que atividades menos formais em sala de aula contribuem para a motivação dos alunos. Na maior parte das atividades, os alunos podiam formar grupos de acordo com suas preferências, independentemente de terem ou não dificuldades. Autores colocam que ouvir atentamente a uma história, fazer questionamentos durante as atividades ou mesmo preparar um prato no refeitório estimulam o engajamento dos alunos nas atividades escolares; o engajamento tem sido associado a ganhos em leitura e matemática ${ }^{(30)}$.

Testar a eficácia da capacitação dos professores em diferentes escolas, medindo o conhecimento, mudanças na postura e aproveitamento das estratégias é importante para diminuir a interferência pessoal do agente aplicador da mudança.

Futuras pesquisas podem replicar o programa, com adaptações de acordo com o ambiente escolar. Estudar os benefícios da comunicação oral nas relações interpessoais e na aprendizagem reafirma a necessidade do profissional fonoaudiólogo em equipes interdisciplinares, seja como clínico ou promotor de saúde.

\section{CONCLUSÃO}

O programa proporcionou melhora em determinadas habilidades sociais do GP: assertividade/desenvoltura do $1^{\circ}$ e do $5^{\circ}$ anos e cooperação/afetividade para alunos do $1^{\circ}$ e do $3^{\circ}$ anos. Os resultados do $3^{\circ}$ e do $5^{\circ}$ anos devem ser analisados com cautela, uma vez que havia diferenças entre GP e GC no 
pré-programa. A melhora do autocontrole apenas no GP no $3^{\circ}$ ano parece estar associada à menor frequência de comportamentos externalizantes neste grupo.

\section{REFERÊNCIAS}

1. Hair NL, Hanson JL, Wolfe BL, Pollak SD. Association of child poverty, brain development, and academic achievement. JAMA Pediatr. 2015;169(9):8229. PMid:26192216. http://dx.doi.org/10.1001/jamapediatrics.2015.1475.

2. Samadzadeh M, Abbasi M, Shahbazzadegan B. Survey of relationship between psychological hardiness, thinking styles and social skills with high school student's academic progress in Arak city. Procedia Soc Behav Sci. 2011;28:286-92. http://dx.doi.org/10.1016/j.sbspro.2011.11.055.

3. Cohen NJ, Farnia F, Bolter NI. Higher order language competence and adolescent mental health. J Child Psychol Psychiatry. 2013;54(7):733-74. PMid:23451725. http://dx.doi.org/10.1111/jcpp.12060.

4. Melby-Lervåg M, Lyster SAH, Hulme C. Phonological skills and their role in learning to read: A meta-analytic review. Psychol Bull. 2012;138(2):32252. PMid:22250824. http://dx.doi.org/10.1037/a0026744.

5. Nicolau CC, Navas AL. Avaliação das habilidades preditoras do sucesso de leitura em crianças de $1^{\circ} \mathrm{e} 2^{\circ}$ anos do ensino fundamental. Rev CEFAC. 2015;17(3):917-26. http://dx.doi.org/10.1590/1982-021620157214.

6. Moghadam SH, Zainal Z, Ghaderpour M. A review on the important role of vocabulary knowledge in reading comprehension performance. Procedia Soc Behav Sci. 2012;66(7):555-63. http://dx.doi.org/10.1016/j. sbspro.2012.11.300.

7. Nalom AF, Soares AJC, Carnio MS. The relevance of receptive vocabulary in reading comprehension. CoDAS. 2015;27(4):333-8. PMid:26398255. http://dx.doi.org/10.1590/2317-1782/20152015016.

8. Reese E, Suggate S, Long J, Schaughency E. Children's oral narrative and reading skills in the first 3 years of reading instruction. Read Writ. 2010;23(6):627-44. http://dx.doi.org/10.1007/s11145-009-9175-9.

9. Sugishita S, Fukushima K, Kasai N, Konishi T, Omori K, Taguchi T, et al. Language development, interpersonal communication, and academic achievement among Japanese children as assessed by the Aladjin. Ann Otol Rhinol Laryngol Suppl. 2012;202(4):35-9. PMid:22616278. http:// dx.doi.org/10.1177/000348941212100405.

10. Del Prette ZA, Del Prette A. Psicologia das habilidades sociais na infância: teoria e prática. Petrópolis: Vozes; 2005.

11. Cárnio MS, Stivanin L, Vieira MP, Martins L, Oliveira V, Carvalho E, et al. Habilidades de consciência fonológica e letramento em crianças de Ensino Fundamental. Rev Soc Bras Fonoaudiol. 2006;11(4):231-42.

12. Hutchinson J, Clegg J. Education practitioner-led intervention to facilitate language learning in young children: An effectiveness study. Child Lang Teach Ther. 2011;27(2):151-64. http://dx.doi.org/10.1177/0265659010397232.

13. Soares AJC, Jaciento LA, Cárnio MS. Memória operacional fonológica e consciência fonológica em escolares ao final do ciclo I do ensino fundamental. Rev Soc Bras Fonoaudiol. 2012;17(4):447-53. http://dx.doi.org/10.1590/ S1516-80342012000400014.

14. Gillam SL, Olszewski A, Fargo JU, Gillam RB. Classroom-based narrative and vocabulary instruction: results of a nearly-stage, non randomized comparison study. Lang Speech Hear Serv Sch. 2014;45(3):204-19. PMid:24687097. http://dx.doi.org/10.1044/2014_LSHSS-13-0008.

15. Sampaio MN, Capellini SA. Intervention program efficacy for spelling difficulties. CoDAS. 2014;26(3):183-92. PMid:25118913. http://dx.doi. org/10.1590/2317-1782/201420140374.

16. Spencer TD, Petersen DB, Adams JL. Tier 2 language intervention for diverse preschoolers: an early-stage randomized control group study following an analysis of response to intervention. American Journal of Speech-Language Pathology. 2015,24:619-36. http://dx.doi.org/10.1044/2015_AJSLP-14-0101.

17. Porta ME, Carrada MA, Ison MS. Phonological awareness intervention and attention efficiency in children at risk: evidence of effectiveness on visual attention. CoDAS. 2016;28(3):314-8. PMid:27253226. http://dx.doi org/10.1590/2317-1782/20162015277.

18. Cabell SQ, Justice LM, McGinty AS, Coster J, Forston LD. Teacherchild conversations in preschool classrooms: Contributions to children's vocabulary development. Early Child Res Q. 2015;30(1):80-92. http:// dx.doi.org/10.1016/j.ecresq.2014.09.004.

19. Szaflarski JP, Altaye M, Rajagopal A, Eaton K, Meng X, Plante E, et al. A 10-year longitudinal fMRI study of narrative comprehension in children and adolescents. Neuroimage. 2012;63(3):1188-95. PMid:22951258. http:// dx.doi.org/10.1016/j.neuroimage.2012.08.049.

20. Ebert KD, Scott CM. Relationships beteween narrative language samples and norm-referenced tests in language assessment of school-age children. Lang Speech and Hear Ser. 2014;45(2):337-50. http://dx.doi. org/10.1044/2014_LSHSS-14-0034.

21. Spinillo AG. A produção de histórias por crianças: a textualidade em foco. In: Correa J, Spinillo AG, Leitão S. Desenvolvimento da linguagem: escrita e textualidade. Bonsucesso: Nau; 2001. p. 73-116.

22. Peterson C, McCabe A. Developmental psycholinguistics: three ways of looking at a child's narrative. New York: Ed. Plenum Press; 1983.

23. INEB: Instituto Nacional de Estudos e Pesquisas Educacionais Anísio Teixeira. Índice de Desenvolvimento da Educação Básica: IDEB - Resultados e Metas [Internet]. Brasília: Ministério da Educação; 2016 [citado em 2012 dez 12]. Disponível em http://ideb.inep.gov.br/

24. Del Prette Z, Freitas LC, Bandeira M, Del Prette A. SSRS - Inventário de Habilidades Sociais, Problemas de Comportamento e Competência Acadêmica para Crianças - Kit Completo. São Paulo: Casa do Psicólogo; 2016.

25. Korem A, Horenczyk G, Tatar M. Inter-group and intra-group assertiveness: adolescents' social skills following cultural transition. J Adolesc. 2012;35(4):85562. PMid:22209662. http://dx.doi.org/10.1016/j.adolescence.2011.12.002.

26. Casali-Robalinho IG, Del Prette ZAP, Del Prette A. Habilidades sociais como preditoras de problemas de comportamento em escolares. Psic Teor e Pesq. 2015;31(3):321-30. http://dx.doi.org/10.1590/0102-37722015032110321330.

27. Del Prette ZAP, Prette AD, Oliveira LA, Gresham FM, Vance MJ. Role of social performance in predicting learning problems: prediction of risk using logistic regression analysis. School Psychology International Journal. 2012;2(6):615-30. http://dx.doi.org/10.1177/0020715211430373.

28. Scivoletto S, Zayat FL, Medeiro M Fo, Serafim AP, Stivanin L, Lacerda J. Intervenção Multidisciplinar em crianças e adolescentes com transtornos do comportamento e problemas com a lei. In: Boarati MA, Pantano T, Scivoletto S, organizadores. Psiquiatria da Infância e adolescência: cuidado multidisciplinar. São Paulo: Manole; 2016. p. 419-52.

29. Valiente C, Eisenberg N, Haugen R, Spinrad TL, Hofer C, Liew J, et al Children's effortful control and academic achievement: mediation through social functioning. Early Educ Dev. 2011;22(3):411-33. PMid:22573931. http://dx.doi.org/10.1080/10409289.2010.505259.

30. Guo Y, Sun S, Breit-Smith A, Morrison FJ, Connor CM. Behavioral engagement and reading achievement in elementary-school-age children: a longitudinal cross-lagged analysis. J Educ Psychol. 2015;107(2):332-47. http://dx.doi.org/10.1037/a0037638.

\section{Contribuição dos autores}

LS participou da elaboração da pesquisa, levantamento da literatura, coleta e análise dos dados, redação do artigo e trâmites do artigo; MSC participou da elaboração da pesquisa, análise dos dados, redação do artigo e revisão final. 